\title{
The importance of $R 202 Q$ polymorphism in clinical expression of Familial Mediterranean Fever
}

\author{
(1) Emre Tekgöz ${ }^{1}$, (1) Fatma İlknur Çınar², (1) Muhammet Çınar ${ }^{1}$, (1) Sedat Yılmaz ${ }^{1}$ \\ 1 University of Health Sciences Turkey, Gülhane Faculty of Medicine, Department of Internal Medicine, Division of Rheumatology, \\ Ankara, Turkey \\ 2University of Health Sciences Turkey, Gülhane Faculty of Nursing, Department of Internal Medicine Nursing, Ankara, Turkey
}

Date submitted:

20.12.2019

Date accepted:

10.02.2020

Online publication date:

15.09.2020

\section{Corresponding Author:}

Emre Tekgöz, MD, University of Health Sciences Turkey, Gülhane Faculty of Medicine, Department of Internal Medicine, Division of Rheumatology, Ankara, Turkey dr.emretekgoz@hotmail.com

ORCID:

orcid.org/0000-0002-0866-1503

Keywords: Familial Mediterranean Fever, MEFV gene mutation, R202Q

\begin{abstract}
Aims: $R 202 Q$ gene polymorphism is frequently encountered in Familial Mediterranean Fever (FMF) patients. We aimed to investigate the relationship between FMF clinical findings and MEFV gene mutations/polymorphisms with a particular attention to R202Q.

Methods: Total of 158 patients with FMF were included in the study that was conducted in a tertiary rheumatology outpatient clinic. The demographic and clinical features, as well as MEFV gene mutations, were recorded in a "Patient Assessment Form". The severity of the disease was evaluated with the FMF-severity score-2. The associations between clinical features and genetic alterations were calculated with the Pearson chi-square test.

Results: The mean age of patients was $24.3 \pm 5.1$ years, the mean delay in diagnosis was $5.6 \pm 6.3$ years, and 155 of the patients $(98.1 \%)$ were male. The percentage of patients stating that they regularly used colchicine was $86.1 \%$, and the mean dose was $1.4 \pm 0.3 \mathrm{mg} /$ day. The most frequent mutation was M694V (76.6\%), and R202Q, M680I and E148Q were found in a descending order (60.8\%, $19.0 \%$ and $13.9 \%$, respectively). M694V/R202Q was the most prevalent compound heterozygosis and found in 16 patients (10.1\%). This mutation (M694V/R202Q) was associated with fewer frequencies of myalgia and peritonitis, and with good response to colchicine.
\end{abstract}

Conclusions: The presence of R202Q polymorphism is associated with FMF, and should be considered in the routine genetic analysis of the disease. In our patients, its co-existence with M694V seems to be associated with good response to colchicine, and to alleviate the severity of the disease expression of M694V, which is known to be associated with severe course.

\section{Introduction}

Familial Mediterranean Fever (FMF) is an autosomal recessive genetic disorder in which recurrent inflammatory involvement of serous membranes such as pleura, peritoneum, and synovium comprises the main clinical feature. Although FMF can be seen in many ethnic groups, it is more frequent in Middle Eastern and Mediterranean descent. The highest prevalence in Turks ranged between 1 per 400 and 1 per 1000 (1). The Mediterranean fever (MEFV) gene is located on the short arm of chromosome 16. There are a total of 10 exons on this gene and FMF-related mutations are mostly in exons 10 and 2. This gene encodes a protein called Pyrin or Marenostrin. Clinical manifestations of FMF are considered to occur due to the inability to control the post-inflammatory process of the incorrectly synthesized 'Pyrin' protein associated with MEFV gene mutations $(2,3)$. A lot of mutations have been identified in the MEFV gene. The appearance of these gene mutations will not always be associated with the disease. Among these, M694V, M694I, V726A, and M680I are the most common disease-related mutations. On the other hand, the clinical significance of some other mutations like R202Q is unclear and their relationship with any clinical feature of FMF has not been clarified yet. In this context, although there have been many efforts to determine genotype-phenotype associations in FMF, there are no consistent data on this subject. In this study, we investigated the relationship between FMF clinical findings 
and MEFV gene mutations, and we tried to emphasize the importance of $R 202 Q$ gene polymorphism in the FMF clinic.

\section{Methods}

\section{Study Design, Selection of Sample, and Setting}

This study was conducted between April 2016 and December 2016. The study was approved by the Gülhane Ethical Review Board (date: April 5, 2016-190, number: 50687469-1491-28916/1648-934) and written informed consent was obtained from each participant. Patients with FMF were invited to participate in the study. The inclusion criteria for the study are (a) being fulfilling the Tel-Hashomer diagnostic criteria (b) having a MEFV gene analysis containing M694V, M680I, M694I, E148Q, V726A, R761H, P369S, A165A, G138G, R202Q, K695R, A744S, and L110P mutations, (c) being aged 18 years and older, (d) absence of mental confusion or any other psychiatric disorder obtained from medical records, (e) being able to speak, read, and write in Turkish, and (f) volunteering to participate in the research. The exclusion criteria are i) having a major psychiatric disease diagnosis, ii) having concurrent terminal illness or being clinically unstable, and iii) having cognitive impairment. Total of 158 patients with FMF were enrolled in the study and were subjected to data analyses.

\section{Data Collection and Procedure}

The demographic and clinical data were collected through face-to-face interviews after the participants had been informed about the purpose of the study. The demographic and clinical features were recorded in a "Patient Assessment Form". The severity of the disease was evaluated with the FMF-severity score-2 (F-SS-2), which consisted of six criteria, including the age onset of clinical findings, the number of affected sites in a single attack, the number of affected sites in the course of the disease, the number of pleuritic attacks during the course of the disease, the number of erysipelas-like erythema attacks during the course of the disease and the colchicine dose used for remission in patients. According to the F-SS-2, the score of 3 or more was classified as severe, the score of 2 was medium, and the score of 1 or below was mild disease severity (4). Also, patients were classified according to clinical attack frequency under colchicine treatment. Those who had no attacks within the last 6 months were considered as "complete remission" and if they had at least 1 episode per month, they were considered as "resistant" or "nonresponsive"(5). MEFV gene mutation analysis was performed with a commercial kit (SNP FMF Real Time Polymerase Chain Reaction Kit, Ankara, Turkey) which works real time polymerase chain reaction method in our hospital.

\section{Statistical Analysis}

Statistical analyses were performed in the IBM SPSS for Windows version 21.0 package program. Numerical variables were summarized by mean \pm standard deviation and categorical variables by number and percentage. The Kolmogorov-Smirnov test was used to examine whether the numerical variables showed normal distribution. The difference in categorical variables between the groups was examined by the chisquare test. The relationship between numerical variables was examined with the Pearson correlation coefficient. Significance level was accepted as $p<0.05$.

\section{Results}

Total of the 158 patients participated in the study, 155 $(98.1 \%)$ were male and $3(1.9 \%)$ were female. The mean age of the patients was $24.3 \pm 5.1$ years. The number of patients having family history of FMF was 100 (63.3\%). The mean age at onset of clinical findings was $11.6 \pm 6.6$ years, whereas the mean age at diagnosis was $17.3 \pm 7.2$ years, and the mean delay in diagnosis was $5.6 \pm 6.3$ years. The number of patients who regularly used colchicine was $136(86.1 \%)$ and the average colchicine dose taken was $1.4 \pm 0.3 \mathrm{mg} /$ day. There were $34(21.5 \%)$ patients in complete remission, and 27 (17.1\%) patients in colchicineresistant or non-responsive group. Ninety four patients (59.5\%) had severe, 38 (24\%) moderate, and $26(16.5 \%)$ had low disease severity levels (Table 1 ).

The most common MEFV gene mutation was M694V. Homozygous and heterozygous M694V mutations were observed in $66(41.8 \%)$ and $55(34.8 \%)$ patients, respectively, and $121(76.6 \%)$ patients had this mutation in total. Mutations of R202Q, M680I, E148Q, and V726A (60.8\%, 19\%, 13.9\% and $8.2 \%$, respectively) were detected with decreasing frequency. Thirty $(19 \%)$ patients had compound heterozygote mutation. The most common type of compound heterozygote mutation was M694V/R202Q and detected in 16 patients (10.1\%). M694V/M680I was detected in $5(3.2 \%)$ patients and M694V/ R761V mutation was found in $2(1.3 \%)$ patients (Table 2$)$.

In terms of the relationship between genotype and phenotype, M694V mutation frequency was significantly higher in patients with family history of FMF, compared to those without family history $(82.0 \%$ vs. $67.2 \%, p=0.035)$. Furthermore, the frequency of M694V mutation was found to be higher in patients with arthritis, compared to those without arthritis $(80.5 \%$ vs. $65 \%$, $p=0.045)$. E148Q mutation frequency increased in patients with history of orchitis $(25 \%$ to $10.7 \%, p=0.029)$. Another significant association between $\mathrm{E} 148 \mathrm{Q}$ mutation and clinical findings was hemodialysis due to end-stage renal failure secondary to FMF in the family $(40 \%$ to $11.2 \%, p=0.005)$. The prevalence of non-periodic myalgia was $34.2 \%$ and the patients with V726A mutation declared not to suffer from this symptom $(p=0.005)$ (Table 3a).

M694V/R202Q compound mutation was associated with an increase in the response rate to colchicine treatment significantly and a decrease in the frequency of myalgia and peritonitis 
attacks $(p=0.012, p=0.016, p<0.001$, respectively). Another rarely observed compound heterozygous mutation, M694V/ M680I, was observed in five patients in total, and associated with acute arthritis $(p=0.016)$ (Table $3 b)$.

In comparison to other mutations, the patients with M694V mutation had higher F-SS-2 severity score $(p=0.01)$. There was no correlation between other mutation types and F-SS-2 severity score (Table 4).

\begin{tabular}{|c|c|}
\hline Characteristics & n (\%) \\
\hline Age (years) (mean $\pm S D)$ & $24.3 \pm 5.1$ \\
\hline \multicolumn{2}{|l|}{ Sex } \\
\hline Male (M) & $155(98.1)$ \\
\hline Female (F) & $3(1.9)$ \\
\hline Family history of FMF & $100(63.3)$ \\
\hline Disease onset (years) (mean $\pm S D$ ) & $11.6 \pm 6.6$ \\
\hline Age at diagnosis (years) (mean $\pm S D)$ & $17.3 \pm 7.2$ \\
\hline Diagnostic delay (year) (mean $\pm S D)$ & $5.6 \pm 6.3$ \\
\hline Colchicine usage and FMF severity score & n (\%) \\
\hline Regular colchicine use & $136(86.1)$ \\
\hline Colchicine dose & $1.4 \pm 0.3$ \\
\hline \multicolumn{2}{|l|}{ Colchicine response } \\
\hline No response to colchicine & $27(17.1)$ \\
\hline Complete response & $34(21.5)$ \\
\hline \multicolumn{2}{|l|}{ FMF-severity score (F-SS-2) } \\
\hline Severe & $94(59.5)$ \\
\hline Moderate & $38(24.1)$ \\
\hline Mild & $26(16.5)$ \\
\hline \multicolumn{2}{|c|}{$\begin{array}{l}\text { Data represented either as the mean } \pm S D \text { or as the frequency. } \\
\text { M: Male, F: Female, FMF: Familial Mediterranean Fever, SD: Standard } \\
\text { deviation, F-SS-2: FMF-severity score-2 }\end{array}$} \\
\hline
\end{tabular}

\section{Discussion}

In this study, we have shown that $\mathrm{R} 202 \mathrm{Q}$ polymorphism in MEFV gene more or less has an effect on the clinical findings of the disease. Hence, the most common mutation after M694V and the most common compound heterozygosity with M694V support the clinical significance of this mutation.

Although many of them are rare, hundreds of variants in MEFV gene mutations have been detected. However, no consistent association was found between these mutations and the clinical manifestations of the disease. While the genotypephenotype relationship in FMF is not revealed inclusively yet, the association between the disease itself and some MEFV gene mutations such as M694V, M694I, V726A, M680I is quite clear (1). In our study, M694V mutation was the most common among MEFV mutations (76.6\%) similarly to previous studies $(6,7)$. The most frequently observed mutations in Turkish and Armenian studies are M694V, M680I, V726A, E148Q (8). Unlike these studies, the second most frequently observed mutation type after the M694V mutation was identified as R202Q in our study. R202Q polymorphism is the most frequently observed polymorphism in MEFV mutations (9). It has been alleged and accepted, at least in part, that this polymorphism in heterozygous patients has no disease-causing effect. On the other hand, there has been a discrepancy about the role of R202Q allele in the clinical expression of FMF. In literature, there have been studies indicating similar frequency rates of heterozygous R202Q allele in FMF patients and healthy controls $(10,11)$. In the same studies, it was not the case for the frequency of the homozygous $\mathrm{R} 202 \mathrm{Q}$ allele, since homozygous $\mathrm{R} 202 \mathrm{Q}$ was higher in the patients with FMF. Heterozygous $\mathrm{R} 202 \mathrm{Q}$ in 59 patients $(37.3 \%)$ in our study is consistent with previous reports. Similar to the results of study completed by Yigit et al. (11), homozygous R202Q polymorphism was found in 37 patients (23.4\%) in our study. Our findings give

\begin{tabular}{|c|c|c|c|}
\hline MEFV mutations & $\begin{array}{l}\text { Presence of any related } \\
\text { mutation } \\
\mathrm{n}, \%\end{array}$ & $\begin{array}{l}\text { Heterozygote } \\
\text { n, \% }\end{array}$ & $\begin{array}{l}\text { Homozygote } \\
\mathrm{n}, \%\end{array}$ \\
\hline M694V & $121(76.6)$ & $66(41.8)$ & $55(34.8)$ \\
\hline R202Q & $96(60.8)$ & $59(37.3)$ & $37(23.4)$ \\
\hline M680I & $30(19.0)$ & $25(15.8)$ & $5(3.2)$ \\
\hline E148Q & $22(13.9)$ & $22(13.9)$ & $0(0.0)$ \\
\hline V726A & $13(8.2)$ & $10(6.3)$ & $3(1.9)$ \\
\hline MEFV compound mutations & \multicolumn{3}{|c|}{ Presence of any related mutation $n, \%$} \\
\hline Any compound heterozygosity & \multicolumn{3}{|l|}{$30(19.0)$} \\
\hline M694V/R202Q & \multicolumn{3}{|l|}{$16(10.1)$} \\
\hline M694V/M680I & \multicolumn{3}{|l|}{$5(3.2)$} \\
\hline M694V/R761V & \multicolumn{3}{|l|}{$2(1.3)$} \\
\hline
\end{tabular}


support to the consideration that $\mathrm{R} 202 \mathrm{Q}$ is one of the causative genetic abnormalities in the pathogenesis of FMF. In addition to the contribution to the debate about whether the R202Q has a role in FMF or not, our study also gives evidence about the clinical significance of the R202Q alteration in patients with FMF. When we compared the compound heterozygous mutations M694V/R202Q with other mutations, we found that M694V/R202Q was associated with fewer frequencies of myalgia and peritonitis, and with good response to colchicine, in other words, with better course of the disease. This finding is somewhat consistent with the study of Çankaya et. al. (12), in which they detected that frequencies of symptoms were lower in the M694V/R202 subgroup. When taken together, these two studies suggest that $\mathrm{R} 202 \mathrm{Q}$ alteration alleviates the disease course in patients with M694V mutation, which is known to be associated with more severe disease.

Colchicine has been used since the 1970s to prevent or at least to reduce frequency and severity of FMF attacks and more importantly to prevent the development of amyloidosis. The use of colchicine in sufficient doses prevents amyloidosis, the most important complication of FMF, and provides amelioration in patients who develop amyloidosis $(3,13)$. However, its preventive effect is applicable only when it is used regularly. We concluded in our study that $136(86.1 \%)$ of patients received

\begin{tabular}{|c|c|c|c|c|}
\hline \multirow{2}{*}{$\begin{array}{l}\text { Clinical finding } \\
\text { No/Yes }\end{array}$} & & \multicolumn{2}{|c|}{ MEFV mutation } & \multirow{2}{*}{$p$ value } \\
\hline & & No & Yes & \\
\hline \multicolumn{5}{|l|}{ M694V } \\
\hline \multirow{2}{*}{ Family history of FMF } & No & $19(32.8)$ & $39(67.2)$ & \multirow{2}{*}{0.035} \\
\hline & Yes & $18(18.0)$ & $82(82.0)$ & \\
\hline \multirow{2}{*}{ Arthritis } & No & $14(35.0)$ & $26(65.0)$ & \multirow{2}{*}{0.045} \\
\hline & Yes & $23(19.5)$ & $95(80.5)$ & \\
\hline \multicolumn{5}{|l|}{ E148Q } \\
\hline \multirow{2}{*}{ Orchitis } & No & $109(89.3)$ & $13(10.7)$ & \multirow{2}{*}{0.029} \\
\hline & Yes & $27(75.0)$ & $9(25.0)$ & \\
\hline \multirow{2}{*}{ Family history of hemodialysis } & No & $127(88.8)$ & $16(11.2)$ & \multirow{2}{*}{0.002} \\
\hline & Yes & $9(60.0)$ & $6(40.0)$ & \\
\hline \multicolumn{5}{|l|}{ V726A } \\
\hline \multirow{2}{*}{ Non-periodic myalgia } & No & $91(87.5)$ & $13(12.5)$ & \multirow{2}{*}{0.005} \\
\hline & Yes & $54(100.0)$ & $0(0.0)$ & \\
\hline
\end{tabular}

\begin{tabular}{|c|c|c|c|c|}
\hline \multirow{2}{*}{$\begin{array}{l}\text { Clinical finding } \\
\text { No/Yes }\end{array}$} & & \multicolumn{2}{|c|}{ MEFV mutation } & \multirow{2}{*}{$p$ value } \\
\hline & & No & Yes & \\
\hline \multicolumn{5}{|l|}{ M694V/R202Q } \\
\hline \multirow{2}{*}{ Peritonitis } & No & $11(64.7)$ & $6(35.3)$ & \multirow{2}{*}{$<0.001$} \\
\hline & Yes & $131(92.9)$ & $10(7.1)$ & \\
\hline \multirow{2}{*}{ Myalgia } & No & $68(84.0)$ & $13(16.0)$ & \multirow{2}{*}{0.016} \\
\hline & Yes & $74(96.1)$ & $3(3.9)$ & \\
\hline \multirow{3}{*}{ Colchicine response } & No & $26(96.3)$ & $1(3.7)$ & \multirow{2}{*}{0.012} \\
\hline & Partial & $90(92.8)$ & $7(7.2)$ & \\
\hline & Complete & $26(76.5)$ & $8(23.5)$ & \\
\hline \multicolumn{5}{|l|}{ M694V/M680I } \\
\hline \multirow{2}{*}{ Arthralgia } & No & $18(85.7)$ & $3(14.3)$ & \multirow{2}{*}{0.017} \\
\hline & Yes & $135(98.5)$ & $2(1.5)$ & \\
\hline \multirow{2}{*}{ Acute arthritis } & No & $148(98.0)$ & $3(2.0)$ & 0.016 \\
\hline & Yes & $5(71.4)$ & $2(28.6)$ & \\
\hline
\end{tabular}




\begin{tabular}{|c|c|c|c|c|c|}
\hline \multirow[t]{2}{*}{ MEFV mutation } & & \multicolumn{3}{|c|}{ FMF-severity score (F-SS-2) } & \multirow{2}{*}{$p$ value } \\
\hline & & Mild, n (\%) & Moderate, $\mathrm{n}(\%)$ & Severe, n (\%) & \\
\hline \multirow[t]{2}{*}{ M694V } & No & $12(32.4)$ & $6(16.2)$ & $19(51.4)$ & \multirow{2}{*}{0.010} \\
\hline & Yes & $14(11.6)$ & $32(26.4)$ & $75(62.0)$ & \\
\hline \multirow{2}{*}{ R202Q } & No & $13(21.0)$ & $13(21.0)$ & $36(58.1)$ & \multirow{2}{*}{0.427} \\
\hline & Yes & $13(13.5)$ & $25(26.0)$ & $58(60.4)$ & \\
\hline \multirow{2}{*}{ E148Q } & No & $21(15.4)$ & $33(24.3)$ & $82(60.3)$ & \multirow{2}{*}{0.693} \\
\hline & Yes & $5(22.7)$ & $5(22.7)$ & $12(54.5)$ & \\
\hline \multirow{2}{*}{ M680I } & No & $23(18.0)$ & $30(23.4)$ & $75(58.6)$ & \multirow{2}{*}{0.567} \\
\hline & Yes & $3(10.0)$ & $8(26.7)$ & $19(63.3)$ & \\
\hline \multirow{2}{*}{ V726A } & No & $23(15.9)$ & $34(23.4)$ & $88(60.7)$ & \multirow{2}{*}{0.587} \\
\hline & Yes & $3(23.1)$ & $4(30.8)$ & $6(46.2)$ & \\
\hline \multirow{2}{*}{ M694V/R202Q } & No & $23(16.2)$ & $34(23.9)$ & $85(59.9)$ & \multirow{2}{*}{0.954} \\
\hline & Yes & $3(18.8)$ & $4(25.0)$ & $9(56.2)$ & \\
\hline
\end{tabular}

colchicine treatment regularly with a mean of $1.4 \pm 0.3 \mathrm{mg} / \mathrm{day}$, consistent with our previous knowledge. Consequently, in this cohort with a high rate of regular colchicine usage, 27 patients (17.1\%) did not respond to treatment despite the maximum dose of colchicine.

Although many scoring systems were established to determine the disease severity, F-SS-2 scoring system was used in our study. This scoring scale, developed by Mor et al. (4), distinguishes severity disease from non-severity disease by over $92 \%$ sensitivity and specificity. As discussed above, the severity of the disease is assessed in terms of response to colchicine treatment and clinical findings. In addition, the MEFV gene mutations that patients have may affect the clinical symptoms in some cases. In this regard, studies have been carried out to demonstrate the prognosis and predict the clinical severity of the disease, that is, the genotype- phenotype relationship. The most striking mutation type in FMF patients in terms of genotypephenotype relationship is M694V. In our study, M694V mutation was associated with more severe disease $(p=0.01)$. The previous studies on this subject supported our findings $(14,15)$. Yilmaz et al. (16) used the Pras severity score differently, and the disease severity score was also high in those carrying the M694V mutation.

$\mathrm{E} 148 \mathrm{Q}$ and $\mathrm{V} 726 \mathrm{~A}$ mutations in our cohort were observed less frequently than mutations M694V, R202Q and M680I. It has been suggested that the E148Q mutation may be a polymorphism with low penetration, but not a mutation that causes the disease (17). With respect to this mutation, another important relationship found in our study was that the $\mathrm{E} 148 \mathrm{Q}$ mutation was associated with the orchitis and family history of hemodialysis due to end-stage renal failure secondary to FMF. A quite similar finding in the literature was reported by Gershoni-Baruch et al. (15), and they found an increased risk of renal amyloidosis as much as those carrying the M694V mutation in those carrying the V726A/E148Q mutation. However, they concluded that the risk of renal amyloidosis was increased by the V726A allele. One of the clinically important findings of our study is related to V726A mutation. Our results suggest a somewhat protective effect of this mutation since non-periodic myalgia was observed in 54 $(34.2 \%)$ patients, but was not observed in patients carrying the V726A mutation. This finding needs further confirmation, but it should be kept in mind that non-periodic myalgia has not been widely examined in genotype-phenotype association studies.

One of the major limitations of our study was the inequality of female and male patient numbers. This may be due to the fact that consecutive patients that met the criteria of inclusion were included and that the majority of the patients followed up were men. Also, mutation studies were not performed in the parents for individuals with compound mutations.

\section{Conclusion}

$\mathrm{R} 202 \mathrm{Q}$ polymorphism is frequently encountered in FMF patients both as heterozygous and homozygous. We think that $\mathrm{R} 202 \mathrm{Q}$ polymorphism has a role in the expression of the disease. It is associated with milder clinical findings, reduced disease severity and increased rates of response to colchicine, when found in combination with M694V, which is known to be associated with severe disease course. In this respect, it can also provide opportunities for clinicians in the followup of patients with FMF, in terms of disease progression and treatment options. For this reason, R202Q polymorphism should be considered in the routine genetic analysis of the disease. 


\section{Ethics}

Ethics Committee Approval: The study was approved by the Gülhane Ethical Review Board (date: April 5, 2016-190, number: 50687469-1491-289-16/1648-934).

Informed Consent: Written informed consent was obtained from each participant.

Peer-review: Externally peer-reviewed.

\section{Authorship Contributions}

Concept: E.T., S.Y., M.Ç., F.I.Ç., Design: E.T., S.Y., M.Ç., F.I.Ç., Data Collection or Processing: E.T., S.Y., M.Ç., Analysis or Interpretation: E.T., M.Ç., F.I.Ç., S.Y., Literature Search: E.T., S.Y., Writing: E.T., S.Y., M.Ç., F.I.Ç.

Conflict of Interest: No conflict of interest was declared by the authors.

Financial Disclosure: The authors declared that this study received no financial support.

\section{References}

1. Alghamdi M. Familial Mediterranean fever, review of the literature. Clin Rheumatol. 2017;36:1707-1713.

2. Migita K, Asano T, Sato S, Koga T, Fujita Y, Kawakami A. Familial Mediterranean fever: overview of pathogenesis, clinical features and management. Immunol Med. 2018;41:55-61.

3. Ozdogan H, Ugurlu S. Familial Mediterranean Fever. La Presse Médicale. 2019;48:61-76.

4. Mor A, Shinar $\mathrm{Y}$, Zaks $\mathrm{N}$, et al. Evaluation of disease severity in familial Mediterranean fever. Semin Arthritis Rheum. 2005;35:57-64.

5. Ozen S, Kone-Paut I, Gül A. Colchicine resistance and intolerance in familial mediterranean fever: Definition, causes, and alternative treatments. Semin Arthritis Rheum. 2017;47:115-120.

6. Duşunsel R, Dursun I, Gündüz Z, Poyrazoǧlu MH, Gürgöze MK, Dundar M. Genotype-phenotype correlation in children with familial Mediterranean fever in a Turkish population. Pediatr Int. 2008;50:208-212.
7. Solak M, Yıldız H, Köken R, et al. Analysis of Familial Mediterranean Fever Gene Mutations in 202 Patients with Familial Mediterranean Fever. Genet Test. 2008;12:341344.

8. Ben-Chetrit E, Touitou I. Familial mediterranean fever in the world. Arthritis Care Res. 2009;61:1447-1453.

9. Bernot A, da Silva C, Petit JL, et al. Non-founder mutations in the MEFV gene establish this gene as the cause of familial Mediterranean fever (FMF). Hum Mol Genet. 1998; 7:1317-1325.

10. Giaglis S, Papadopoulos V, Kambas K, et al. MEFV alterations and population genetics analysis in a large cohort of Greek patients with familial Mediterranean fever. Clin Genet. 2007;71:458-467.

11. Yigit S, Karakus N, Tasliyurt T, Kaya SU, Bozkurt N, Kisacik B. Significance of MEFV gene R202Q polymorphism in Turkish familial Mediterranean fever patients. Gene. 2012;506:43-45.

12. Çankaya T, Bora E, Torun Bayram M, et al. Clinical significance of R202Q alteration of MEFV gene in children with familial Mediterranean fever. Turkish $\mathrm{J}$ Rheumatol 2015;30:51-56.

13. Livneh A, Zemer D, Langevitz P, Laor A, Sohar E, Pras M. Colchicine treatment of AA amyloidosis of familial Mediterranean fever. An analysis of factors affecting outcome. Arthritis Rheum. 1994;37:1804-1811.

14. KucukA, Gezer I, Ucar R, KarahanA. Familial Mediterranean Fever. Acta Medica. 2014;57:97-104.

15. Gershoni-Baruch R, Brik R, Shinawi M, Livneh A. The differential contribution of MEFV mutant alleles to the clinical profile of familial Mediterranean fever. Eur J Hum Genet. 2002;10:145-149.

16. Yilmaz E, Dinçel N, Sözeri B, et al. Familial mediterranean fever in children from the Aegean region of Turkey: Gene mutation frequencies and phenotype-genotype correlation. Turkish J Med Sci. 2015;45:1198-1206.

17. Tchernitchko D, Legendre M, Cazeneuve C, Delahaye A, Niel F, Amselem S. The E148Q MEFV allele is not implicated in the development of familial Mediterranean fever. Hum Mutat. 2003;22:339-340. 